\title{
Editorial
}

\section{The Journal's experience of the first year}

IndiaClen had decided to start a Journal of the network way back in the 1990s. There were a few pioneering attempts and a couple of issues were published. The demand for a journal was, therefore, unmet till 2013, when Clinical Epidemiology and Global Health was launched in the IndiaClen Conference held in King George's Medical University, Lucknow. The first editorial was very aptly titled by Fletcher and Fletcher as, " $\mathrm{A}$ new Journal is Born". ${ }^{1}$

The journal is still in its infancy but the first year went well. There was a steady stream of articles submitted. To be precise, there were 51 submissions for the three issues of volume 1 . Most of the submissions were from aspiring authors. Some established researchers also submitted their research manuscripts. The network and editors took upon themselves to build the capacity of the aspiring authors and ensured that the highest scientific publishing standards were maintained. Hence all the 51 new submissions were submitted for revision after initial review. The areas covered were epidemiology, social science, health economics and global and public health. There is a special students' section as there was a felt need to encourage publication among medical graduates and postgraduates. $^{2}$

The average number of days between the date the manuscript was received and the first decision was around 25 days. This was possible with the contributions from 65 of the reviewers who submitted their comments of the 149 invited for review. While some of the reviewers were members of the IndiaClen network, large numbers were selected by matching their areas of expertise. Reviewers with high $\mathrm{H}$ index were selected. In the first year, the reviewers in the first review recommended acceptance of manuscript in $21.5 \%$ cases, major revision in $26.2 \%$, and minor revision in $32.3 \%$ and rejection in $20 \%$. After revisions and re-reviews, the final editorial rejection rate was about $9 \%$. We hope to get more and more reviewers accepting our invitation as the journal establishes itself. The Journal is truly global with submissions from Asia, Africa and North America.

For wide dissemination of knowledge the journal does not have any publication fees. It is freely available online at www. ceghonline.com. However, there is always the issue of funding and sustainability. We have to find funds for the journal through advertisement, by internal generation of funds within the network, and support of likeminded organizations. We have been generously supported by the Effective Health Care Research Consortium. I hope more organizations will come forward to support the journal.

It is very encouraging to note that in just last one year, our first year of 2013 there have been about eight thousand page views, a number which has filled us with enthusiasm. This is by no means a small number. The Journal users come from 51 countries across all the continents, namely, Asia, Australia, South and North America, Africa, Europe. Leading usage was from India, US, GB, Canada, Egypt, Indonesia, Germany, Peru, Iran, Kenya, Mexico and Nepal.

In the first year and into the second year the Journal published and plans to publish research manuscripts pertaining to a specific theme. The journal also published the recommendations of annual IndiaClen conference ${ }^{3}$ as well as the abstracts of research presentations in the Annual IndiaClen conference held in Lucknow in March 2013. The editors have been advising electronically. As the journal matures and evolves we hope to have more activities for the promotion of the journal. The number of online journals is increasing day by day. Only the quality and added value of Clinical Epidemiology and Global Health will ensure that we are cited as one of the best in this area. We begin the second year with greater enthusiasm to spread the knowledge and understanding of clinical epidemiology and global health. This is a global call for support for the scientific venture of the IndiaClen network. We will be applying for indexing in almost all reputed sites by the end of this year. I look forward to another successful year of publishing.

\section{R E F E R E N C E S}

1. Fletcher RH, Fletcher SW. A new journal is born: clinical epidemiology and global health. Clin Epidemiolog Global Health. 2013;1:1-2.

2. Awasthi S. Biomedical publications - a neglected art in medical education in India. Clin Epidemiolog Global Health. 2013;1:3-4.

3. IndiaClen 2013 Annual Conference Group. IndiaClen recommendations for improving postgraduate medical research \& publication. Clin Epidemiolog Global Health. 2013;1:54-57. 
Shally Awasthi

Professor, Department of Pediatrics, King George's Medical

University, Lucknow, Uttar Pradesh, India

Editor-in-Chief, Clinical Epidemiology and Global Health, India

E-mail address: editorcegh@gmail.com http://dx.doi.org/10.1016/j.cegh.2014.02.001 2213-3984/Copyright @ 2014, INDIACLEN. Publishing Services by Reed Elsevier India Pvt Ltd. All rights reserved.

\section{Obituary}

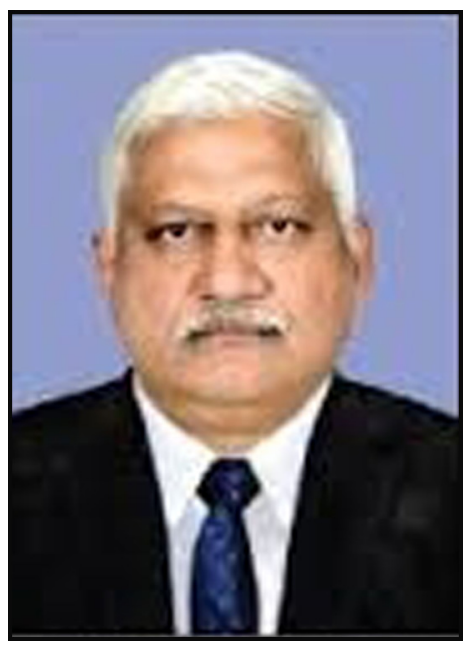

Dr Deoki Nandan left for his heavenly abode on 6th December, 2013. He was a renowned public health specialist, a member of the IndiaCLEN family and on the Editorial Board the Journal Clinical Epidemiology and Global Health. He was an enthusiastic researcher, astute academician and a generous friend and mentor to many. He was always ready to support and promote a just cause.

Through out his illustrious career, he served as Chairman, Uttar Pradesh Secondary Education Service Selection Board, Chancellor of Santosh University, Ghaziabad, Director of National Institute of Health \& Family Welfare, New Delhi and Principal/Dean \& Chief of Hospital, S N Medical College, and Agra. He had also worked as consultant in many international Organizations e.g. WHO-SEARO, UNICEF, CARE-India, EPOS, Population Council, MOST-India and USAID. He was member of many state level committees and National Technical Expert Committees specifically for AIDS, IMCI and Child Health. He participated in many IndiaCLEN network projects.

His demise has left a void in the field of Public Health. IndiaCLEN family pays homage to him. May his soul rest in peace. 